\title{
Endothelialization following Flow Diversion for Intracranial Aneurysms: A Systematic Review
}

\author{
D. Ravindran, (D) M.M. Salem, (D) A.Y. Alturki, (D)A.J. Thomas, (D) C.S. Ogilvy, and (D).M. Moore
}

\begin{abstract}
BACKGROUND: The underlying mechanism of action of flow diverters is believed to be the induction of aneurysm thrombosis and simultaneous endothelial cell growth along the device struts, thereby facilitating aneurysm exclusion from the circulation. Although extensive attention has been paid to the role of altered cerebrovascular hemodynamics using computational fluid dynamics analyses, relatively less emphasis has been placed on the role of the vascular endothelium in promoting aneurysm healing.
\end{abstract}

PURPOSE: Our aim was to systematically review all available literature investigating the mechanism of action of flow diverters in both human patients and preclinical models.

DATA SOURCES: A systematic search of PubMed, Cochrane Central Register of Controlled Trials MEDLINE, EMBASE, and the Web of Science electronic data bases was conducted in accordance with the Preferred Reporting Items for Systematic Reviews and Meta-Analyses guidelines.

STUDY SELECTION: We selected articles assessing the role of endothelialization in flow-diverter treatment of cerebral aneurysms, including both preclinical and clinical studies.

DATA ANALYSIS: Ten articles were eligible for inclusion in this review. Two assessed endothelialization in human patients, while the other 8 used preclinical models (either rabbits or pigs).

DATA SYNTHESIS: Methods used to assess endothelialization included optical coherence tomography and scanning electron microscopy.

LIMITATIONS: A limitation was the heterogeneity of studies.

CONCLUSIONS: Current data regarding the temporal relationship to flow-diverter placement has largely been derived from work in preclinical animal models. Whether these cells along the device struts originate from adjacent endothelial cells or are the result of homing of circulating endothelial progenitor cells is equivocal.

ABBREVIATIONS: Ang-1 = angiopoietin-1; $C D 31$ = cluster of differentiation 31; $C D 34=$ cluster of differentiation 34; EPCs $=$ endothelial progenitor cells; PED = Pipeline Embolization Device; PRISMA = Preferred Reporting Items for Systematic Reviews and Meta-Analyses; Tie2 = cell-surface receptor that binds and is activated by the angiopoietins

$\mathbf{F}$ ow diversion has revolutionized the treatment of select intracranial aneurysms, representing both a safe and efficacious alternative to open microsurgery and other endovascular modalities. $^{1,2}$ In contrast to devices used in other vascular beds, the

\footnotetext{
Received October 3, 2018; accepted after revision December 8.
}

From the Neurosurgical Service, Beth Israel Deaconess Medical Center, Harvard Medical School, Boston, Massachusetts.

Please address correspondence to Justin M. Moore, MD, PhD, Neurosurgical Service, Beth Israel Deaconess Medical Center, 110 Francis St, Suite 3B. Boston, MA 02215-5501; e-mail: justinmurraymoore@gmail.com

三 Indicates article with supplemental on-line table.

http://dx.doi.org/10.3174/ajnr.A5955 cellular and molecular mechanisms underpinning their mechanism of action have not been as well-characterized, despite an exponential increase in their use in recent years. Aneurysm occlusion via flow diversion has traditionally been proposed to occur by 2 predominant overarching processes: 1) intra-aneurysmal thrombosis following device-related disruption of blood flow, and 2) provision of a scaffold for endothelial cell growth at the aneurysmal neck by the device itself. ${ }^{3}$ However, it remains unclear which of these processes is most critical in promoting aneurysmal obliteration.

Initial global endothelialization along the flow-diverting stent and device endothelialization across the neck are crucial events 


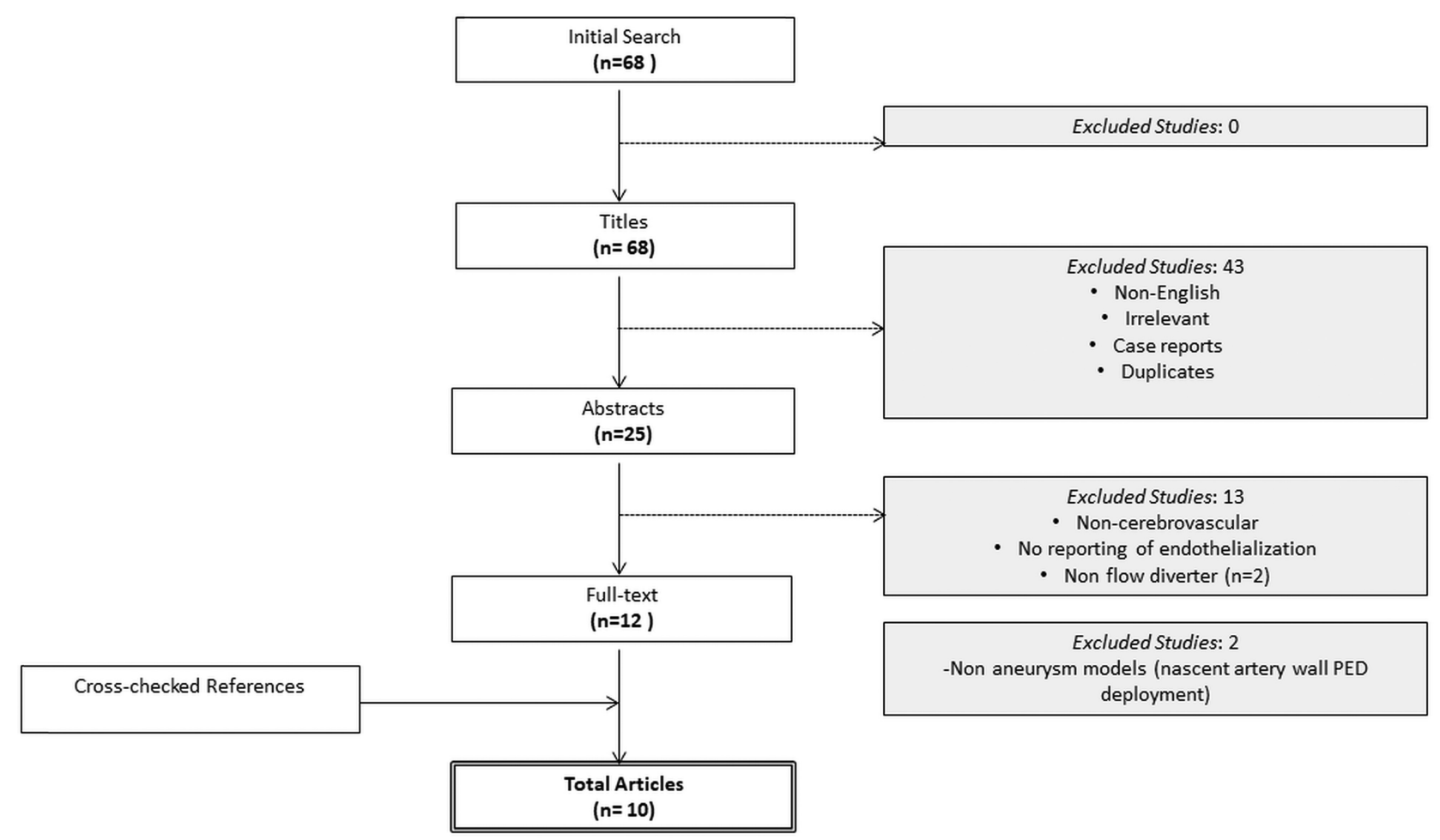

FIG 1. PRISMA flow chart of articles.

for facilitating aneurysm healing; the aneurysm remains at risk of rupture while this process occurs. ${ }^{4,5}$ Mismatch between successful angiographic aneurysm occlusion and MR imaging-visible aneurysm residual and controversy regarding optimal dual-antiplatelet therapy and its duration suggest that greater understanding of flow-diverter endothelialization may aid in optimizing successful aneurysm treatment. Furthermore, an improved understanding of endothelization may help identify patients whose aneurysms are unlikely to be obliterated or to recur following flow-diverter placement. Thus, we performed a systematic review of all available literature investigating the overall device endothelialization of flow diverters in both human patients and preclinical models.

\section{MATERIALS AND METHODS}

\section{Literature Search Strategy}

This review was conducted according to the Preferred Reporting Items for Systematic Reviews and Meta-Analyses (PRISMA) guidelines. Electronic searches were conducted using Ovid MEDLINE, PubMed, EMBASE, the Cochrane Central Register of Controlled Trials, and the Web of Science from dates of inception until April 2018. To maximize the sensitivity of the search criteria, we combined the following terms: "flow diverter," "flow diversion," "flow-diverting stent," "Pipeline Embolization Device," "mechanism," "endothelial," and "endothelialization" as either key words or MeSH terms. References from multiple articles were additionally searched to retrieve any studies examining outcomes not found during the initial literature search.

\section{Selection Criteria}

Inclusion criteria for eligible studies in this systematic review were all studies reporting the use of any flow-diverting stent and any mention of endothelial healing. All abstracts were independently screened by 2 reviewers (K.R., M.M.S.). Case reports, conference presentations, editorials, and non-English studies were excluded.

\section{RESULTS}

A total of 68 references were identified through a search of 5 electronic data bases (Fig 1). Following exclusion of duplicate and irrelevant references and after detailed abstract and title screening, 10 references directly relating to endothelialization were included per the search criteria (On-line Table). ${ }^{5-14}$ Two of the included references studied endothelialization in human patients. ${ }^{7,14}$ The remainder of the included articles used preclinical animal models, constituting pigs $(n=1)$ and rabbits $(n=$ 7 ). Methods used to investigate endothelial coverage of flowdiverting stents included scanning electron microscopy and optical coherence tomography.

\section{DISCUSSION}

\section{Mechanisms of Aneurysm Occlusion: Animal Data}

Animal models of aneurysms have proved critical at providing histopathologic data following Pipeline Embolization Device (PED; Covidien, Irvine, California) deployment, given the difficulty in obtaining human data. However, limitations in translating results from animal models into human patients still exist due to subtle anatomic variances and different hemodynamic environments.

Computational fluid dynamics analyses of elastase-induced aneurysms in rabbits have suggested that a reduction of flow velocity with secondary induction of thrombosis is the foremost mechanism of aneurysm exclusion. ${ }^{15}$ At least at the aneurysmal 
dome, diminished flow velocity may thus serve as the key driver of aneurysm healing. The close relationship between lower aneurysmal flow velocities and shorter occlusion times further supports this argument. ${ }^{16}$ In a 2007 study, Kallmes et $\mathrm{al}^{3}$ used a rabbit elastase model of saccular aneurysms to histologically demonstrate the presence of unorganized thrombus in aneurysm domes at 1 month, with an $88 \%$ rate of complete occlusion. Although the study was limited to only 6 subjects, intimal hyperplasia along the struts across the aneurysm neck was observed in 4 subjects at 6 months following PED deployment, with minimal intimal hyperplasia observed along the parent artery distal to the aneurysm. Moreover, in this study, scanning electron micrography demonstrated contiguity between the endothelium of the parent artery and the endothelial cells covering the stent. However, the patency of smaller branch arteries led the authors to conclude that intraaneurysmal thrombosis was the foremost mechanism of aneurysmal exclusion, despite intimal hyperplasia being observed along device struts at 1 month posttreatment.

A similar study in rabbits by Kadirvel et $\mathrm{al}^{5}$ showed complete endothelialization on the PED surface as early as 1 week following deployment in the setting of complete occlusion, as well as at 8 weeks posttreatment. This appears to suggest that endothelialization following PED placement occurs in 2 phases: rapidly, at the parent artery and slowly at the aneurysmal neck, with the latter requiring an underlying scaffold of smooth-muscle cells. ${ }^{5}$ In particular, angiopoietin-1 (Ang-1) is an established proangiogenic factor, capable of inducing vessel remodeling following injury through interactions with the cell-surface receptor that binds and is activated by the angiopoietins (Tie2), expressed at the vascular endothelial surface. ${ }^{17}$ Most important, in the bone marrow, the subsequent Ang-1/Tie2 complex signaling maintains the undifferentiated state of hematopoietic stem cells, precursors to bone marrow-derived endothelial progenitor cells, and is also upregulated in brain endothelial cells following cerebral ischemia. ${ }^{18-20}$ Vascular endothelial growth factor released by local endothelium in response to injury and foreign matter is also shown to upregulate Ang-1 locally, and additionally, both factors are expressed by bone marrow stem cell subtypes. ${ }^{21,22}$ Most important, histopathologic analyses failed to reveal the presence of solitary thrombi in the absence of overlying smooth-muscle and endothelial cells.

Where tissue islands were observed, these were composed primarily of monocytes and macrophages. Notably, the antiplatelet regimen commonly used in animals has been premedication with aspirin and clopidogrel with maintenance of dual-antiplatelet therapy for 1 month following PED placement. With experimental aneurysms tending toward occlusion at around 2 months postPED in the rabbit model, the duration of the dual antiplatelets may be somewhat short. Endothelialization, therefore, may, accordingly, be limited due to presence of organized thrombus and platelets along the device struts hindering effective neointima formation. In incompletely occluded aneurysms, patchy islands of endothelial cells are observed in rabbits after cessation of dualantiplatelet therapy. ${ }^{5}$ The role of the clopidogrel response and pharmacogenomic profiles in the rabbit model is also another factor that perhaps warrants consideration and may influence endothelialization profiles.
Recently, the Pipeline Flex with Shield technology (Medtronic Neurovascular, Irvine, CA) a second-generation flow-diverter adaptation of the PED Flex incorporating a phosphorylcholine coating along the device struts to reduce thrombogenicity has been studied in pre-clinical models. Preliminary work in a pig aneurysm model has demonstrated significantly higher neointimal thickness with Shield-versus-non-surface-modified flow diverters and a trend toward earlier neointima formation, as determined by optical coherence tomography. ${ }^{12}$ The surface modification of the Shield technology with phosphorylcholine polymers allows greater adsorption of fibronectin, a cell-cell adhesion molecule that is normally present on the subendothelium and is exposed following endothelial injury. ${ }^{23}$ Fibronectin binds to sites on the modified stent and is able to stimulate local angiogenesis through integrin binding on endothelial cells. ${ }^{24}$ Thus, the surfacemodified Shield may (in theory) accelerate endothelialization, though this has yet to be clinically demonstrated.

Although this study provides some insight into the time course of endothelialization along flow-diverting stents in large-mammal animal models, the ability to draw further conclusions is hampered by the lack of aneurysm creation in this model. As indicated by computational fluid dynamics analyses, the vascular environment at the aneurysm neck is substantially different from that in the nascent arterial wall. ${ }^{25}$ Secretion of matrix metalloproteinases and transforming growth factor $\beta$ by fibroblasts and myofibroblasts, in particular, creates an inflammatory milieu that leads to a prothrombotic, activated vascular endothelium.

Conversely, Parameswaran et $\mathrm{al}^{26}$ have recently shown the presence of cluster of differentiation $31(\mathrm{CD} 31+)$ cells in aneurysmal segments from a rabbit experimental aneurysmal model, in the absence of any endovascular intervention. Most interesting, the authors demonstrated a temporal relationship in unintervened aneurysm endothelialization, with an initial endothelial denudation occurring up to $4-8$ weeks following aneurysm creation-as evidenced by the qualitative reduction in whole-mount en face immunostaining for CD31+ cells-and subsequent repopulation by endothelial cells occurring at 12 weeks.

Perhaps some of the strongest evidence of flow-diverter endothelialization in animals has been provided by work done in a rabbit aneurysm model, using immunogold labelling scanning electron microscopy to visualize endothelial coverage in harvested arteries. ${ }^{11}$ Using biotinylated cluster of differentiation 34 $(\mathrm{CD} 34+)$ antibodies, a surface marker of endothelial progenitor cells, conjugated to streptavidin gold nanoparticles in an indirect immunolabeling assay, the study authors showed $87 \%-90 \%$ total tissue coverage along the flow diverters up to 60 days postimplantation. In contrast to prior work, these results suggest that circulating endothelial progenitor cells may provide a greater contribution to initial endothelialization than previously believed. However, this study is limited by the following: 1) use of custommade flow diverters with different porosities compared with commercially available devices, and 2) the histology was performed on harvested arterial segments, and it is unclear whether the flow diverter was wholly contained within the harvested segment. Finally, lack of assaying for mature endothelial cells (CD31+ CD34-) early on may have overlooked any hyperacute contribu- 


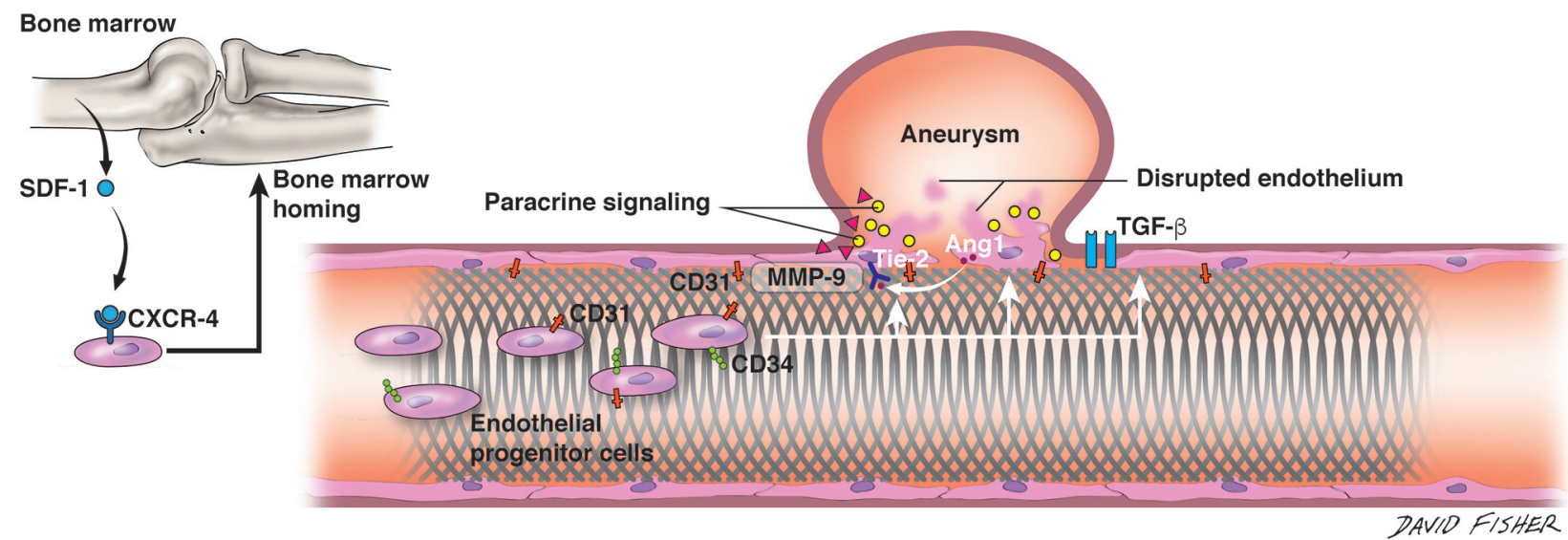

FIG 2. Endothelialization along the flow-diverting stent. Interplay among the flow-diverting stent, native vessel endothelium, molecular factors at aneurysm dome, and circulating endothelial progenitor cells is depicted in cartoon format. Stromal cell-derived factor 1 (SDF-1) released from the bone marrow binds to the C-X-C chemokine receptor type 4 (CXCR-4) receptor on circulating EPCs and directs homing of these cells to the bone marrow. At the site of flow-diverter placement, circulating EPCs (shown as CD31+ CD34+) are seen along device struts. At the aneurysm dome, several molecules, including matrix metalloproteinase-9 (MMP-9), act to stimulate vascular repair. Ang-1 is furthermore released from the disrupted endothelium, where its prorepair action is mediated by the Tie2 receptor expressed on the vascular endothelium. TGF- $\beta$ indicates transforming growth factor $\beta$. Artist: David Fisher, Dept of Neurosurgery, University of Alabama-Birmingham. Published with permission.

tion to endothelialization by the action of locally derived endothelial cells (Fig 2).

\section{Wall Apposition}

In the coronary vasculature, incomplete stent apposition has been strongly associated with in-stent thrombosis. ${ }^{27}$ Congruently, in a study of 41 elastase-induced saccular aneurysms in rabbits, aneurysms with histologically graded good wall apposition following PED treatment had higher angiographic occlusion rates than those with poor wall apposition treatment. ${ }^{13}$

\section{Device Sizing, Pore Density, Metal Coverage: How Do They Affect Occlusion?}

To achieve good proximal apposition, conventionally operators tend to choose "oversized" devices to attain adequate metal coverage at the ostium, thus enhancing aneurysmal occlusion. In comparison with the large repository of data that exists in the coronary literature regarding stent endothelialization, it would appear that both density and material influence subsequent endothelialization. However, it has been reported that neither pore density nor metal coverage has significant association with aneurysmal occlusion. ${ }^{28}$ The study authors noted, expectedly, that ostial diameter was inversely correlated with occlusion.

\section{Mechanisms of Aneurysm Occlusion: Human Data}

Attempts at elucidating the interplay between thrombosis and endothelialization as pivotal mechanisms for aneurysmal exclusion in human patients have been restricted to a handful of studies with small sample sizes. The requisite for a histopathologic demonstration of the endothelial cell phenotype along the stent has thus largely limited investigations to postmortem analyses of harvested arterial segments.

The relative contribution of intra-aneurysmal thrombus formation, as a mechanism of aneurysm exclusion, has been supported by computational fluid dynamics analyses of postPED-treated hemodynamics. Flow-diverter therapy results in reductions in aneurysmal inflow and wall shear stress that provide an environment for promoting parent vessel remodeling. ${ }^{29}$ Intracranial aneurysms treated with flow diversion with shorter times to occlusion have also been reported to exhibit different hemodynamic conditions than those with longer occlusion times, with a significantly lower mean aneurysmal velocity, inflow rate, and shear rate observed in this former group. ${ }^{16}$

Currently, meaningful histopathologic data of intracranial aneurysms treated with flow diverting stents remain scant. Studies to date in human patients have largely been confined to occlusion rates based on angiographic correlation. Dai et $\mathrm{al}^{30}$ have reported the histopathologic results of a solitary case of a basilar tip aneurysm treated with the PED and demonstrated neointimal hyperplasia along the aneurysm neck interface. Further postmortem histopathologic analysis of 5 giant fusiform aneurysms treated with PEDs by Szikora et al, ${ }^{14}$ in 2015 , failed to demonstrate any organized thrombus at 13 months posttreatment, despite angiographic evidence of complete occlusion. Indeed, portions of the PED within the parent artery were shown to be covered with neointima, even in the absence of detectable smooth-muscle cells. Most important, endothelialization was not observed in sections of the stent placed inside the aneurysm itself, suggesting that contact with a physiologically intact vascular wall may be necessary. ${ }^{14}$ However, in a study of 13 aneurysms that were initially treated with the PED but subsequently ruptured, intra-aneurysmal thrombus was identified in all cases. ${ }^{31}$ The authors hypothesized that persisting intraluminal thrombus, triggering autolytic vessel wall degradation, contributed to aneurysmal rupture. Of note, only 2 cases in this study were examined histopathologically, with both exhibiting unorganized thrombi (On-line Table).

Recent work by our group has demonstrated the angiographic appearance of separation of the parent vessel from aneurysms following PED placement, termed the "collar sign," in incompletely occluded aneurysms. ${ }^{7}$ We have hypothesized that this represents endothelialization along the stent surface in juxtaposition to the aneurysmal neck. Paradoxical incomplete aneurysm occlusion following PED placement at 6-month follow-up may be po- 
tentially explained via the existence of interspersed channels between regions of neointimal hyperplasia, still allowing blood flow, corroborated by a case report by Dai et al. ${ }^{30}$ Similarly, endothelialization has been shown to be a driving factor in determining aneurysmal exclusion in intracranial aneurysms treated by coil embolization. ${ }^{32}$ However, histologic analyses suggest that organized thrombus formation is a greater driver of healing following coil deployment compared with flow diversion. Not only does the time course and natural history of healing appear to differ with coil treatment versus flow diversion, the cell mediators also appear to be different, with the fibroblasts and myofibroblasts playing larger roles. ${ }^{4}$ Histopathologic analysis of aneurysm tissue harvested postmortem from human patients treated with bare platinum coils has shown the presence of early neointima, along with collagen-rich tissue along device coils. ${ }^{33}$ Following aneurysm treatment with bioactive coil deployment, further postmortem studies have failed to demonstrate the presence of endothelium within harvested tissue in the acute period. ${ }^{34}$

\section{Endothelial Cells on Stents: Where Do They Come From?}

The origin of endothelial cell strut coverage observed following flow-diverter therapy remains unclear. Endothelial cells along the stent may either arise de novo through paracrine signaling from adjacent endothelial cells or via differentiation of peripherally circulating bone marrow-derived endothelial progenitor cells (EPCs). To date, studies have used an array of immunohistochemical techniques in animal models to demonstrate cell origin by assaying for CD34 and CD31 surface expression, adhesion molecules expressed at the cell surface of undifferentiated EPCs, and mature endothelial cells, respectively.

In the coronary vasculature, in situ endothelialization following stent placement is believed to occur through a combination of cell migration from surrounding endothelium in conjunction with the adhesion of circulating EPCs to stent struts under the influence of secreted angiogenic factors. ${ }^{35}$ The stromal-derived factor $1 / \mathrm{C}-\mathrm{X}-\mathrm{C}$ chemokine receptor type 4 axis plays an important role in the migration of EPCs in the context of both angiogenesis and vascular repair.

Few studies have examined the source of endothelial coverage on flow-diverter stents used in intracranial aneurysms. The autologous transfusion of cultured fluorescently labeled EPCs in a rabbit model of flow diverter-treated aneurysms demonstrated the localization of fluorescence signal to the subendothelial space and device struts, though there was no statistically significant difference in the number of endothelial cells between transfused and nontransfused groups. ${ }^{10}$ The study of Kadirvel et $\mathrm{al}^{5}$ using a similar animal model, however, failed to demonstrate any CD34+ cells along device struts, suggesting that observed endothelial cells had not originated from circulating EPCs. The absence of cells derived from EPCs even at 8 weeks following aneurysmal occlusion is intriguing, though only accurately demonstrable through bone marrow transplantation experiments, which were not performed in the study. While comparisons are often made between coronary stents and even aortic grafts, the porosity and composition of the flow-diverting stent-and indeed cerebrovascular hemodynamics - arguably make extrapolation on underlying mechanisms difficult. Indeed, in the coronary vasculature, expe- rience with stents coated with antibodies specific for blood-derived endothelial progenitor cells has shown increased stent endothelial coverage. ${ }^{36}$ Notably, in the postmortem series of Szikora et al, ${ }^{14}$ no endothelial cells staining positive for CD34, a marker of circulating endothelial progenitor cells, were observable along the flow diverter; this finding was similarly corroborated in the rabbit aneurysm model. . $^{3,16}$

In a recent follow-up study by $\mathrm{Li}$ et $\mathrm{al},{ }^{9}$ administration of a pharmacologic antagonist of the stromal cell-derived factor-1/ CXC chemokine receptor type 4, AMD 3100, showed increased neointimal thickness along the flow-diverting stent in a rabbit aneurysm model. Moreover, quantitative polymerase chain reaction determination of messenger RNA in the neointimal cells growing along the stent surface showed increased Tie2 and vascular endothelial cadherin expression levels. However, the pharmacodynamics of AMD 3100 have not yet been clearly elucidated, and whether extramedullary $\mathrm{C}-\mathrm{X}-\mathrm{C}$ chemokine receptor type 4 expression may have contributed to the observed effect was not completely discussed. Despite early enthusiasm surrounding their potential, the putative role of EPCs, in the context of capture stents coated with an anti-CD34 antibody, has not yet been convincingly demonstrated in the coronary literature.

\section{Limitations}

Our study has several limitations. First, the heterogeneity of the studies and lack of standardized protocols hinder the scope of the analysis and make comparisons difficult. The small sample size of most available articles is an additional limitation. Most data are drawn from animal models, in which subtle anatomic and hemodynamic differences from human circulation could question the generalizability of such drawn conclusions. The included human studies were, moreover, small case series and reports, with the small sample size making it difficult to extrapolate and draw meaningful conclusions. Indeed, there was an overall paucity of data on the subject, despite the widespread use of the PED.

\section{Future Directions}

The vascular endothelium lies at a critical interface that, when exposed to subtle alterations in the hemodynamic state, becomes vasoactive. The intimate interaction between stent struts and endothelium thus makes this structure an ideal therapeutic target for optimizing aneurysm occlusion. Current translational research is aimed at designing low-profile stents that maximize endothelialization, while balancing the risk of in-stent stenosis and ensuing endothelial hyperplasia. While in-stent restenosis remains a persisting problem in the coronary vasculature, the incidence following flow-diverting stent placement is low. Thus, the endothelium may provide the source of a potential biomarker that, if identified, may predict successful aneurysm occlusion based on patient biology. In the coronary literature, several key molecules have drawn attention in recent years, including C-reactive protein, eosinophilic cationic protein, matrix metalloproteinases, and the lectins, though difficulties in providing quick, commercially available laboratory assays have slowed efforts. ${ }^{37}$ An effective biomarker must have certain characteristics, including high specificity and sensitivity and cost-effectiveness. However, further mechanistic insight into the key signaling pathways 
involved in flow diverter-induced aneurysm healing is warranted, to better identify therapeutic targets. Application of highthroughput "omics" analyses may allow an increased understanding of these cellular and molecular mechanisms.

\section{CONCLUSIONS}

Stent endothelial cell coverage is a predominant mechanism by which aneurysm healing occurs following flow-diverter treatment. Current data regarding the temporal relationship to flowdiverter placement has largely been derived from work in preclinical animal models. Whether these cells originate from adjacent endothelial cells or are the result of homing of circulating endothelial progenitor cells is equivocal. Further investigation into the underlying signaling mechanisms is required to identify potential therapeutic targets for optimizing aneurysm occlusion.

\section{REFERENCES}

1. Becske T, Kallmes DF, Saatci I, et al. Pipeline for uncoilable or failed aneurysms: results from a multicenter clinical trial. Radiology 2013; 267:858-68 CrossRef Medline

2. Kallmes DF, Hanel $\mathrm{R}$, Lopes $\mathrm{D}$, et al. International retrospective study of the Pipeline embolization device: a multicenter aneurysm treatment study. AJNR Am J Neuroradiol 2015;36:108-15 CrossRef Medline

3. Kallmes DF, Ding YH, Dai D, et al. A new endoluminal, flow-disrupting device for treatment of saccular aneurysms. Stroke 2007;38: 2346-52 CrossRef Medline

4. Brinjikji W, Kallmes DF, Kadirvel R. Mechanisms of healing in coiled intracranial aneurysms: a review of the literature. AJNR Am J Neuroradiol 2015;36:1216-22 CrossRef Medline

5. Kadirvel R, Ding YH, Dai D, et al. Cellular mechanisms of aneurysm occlusion after treatment with a flow diverter. Radiology 2014;270: 394-99 CrossRef Medline

6. Ding Y, Dai D, Kallmes DF, et al. Preclinical testing of a novel thin film nitinol flow-diversion stent in a rabbit elastase aneurysm model. AJNR Am J Neuroradiol 2016;37:497-501 CrossRef Medline

7. Griessenauer CJ, Gupta R, Shi S, et al. Collar sign in incompletely occluded aneurysms after Pipeline embolization: evaluation with angiography and optical coherence tomography. AJNR Am J Neuroradiol 2017;38:323-26 CrossRef Medline

8. Li Z, Zhao R, Fang X, et al. Recombinant human SDF-1 $\alpha$ administration accelerates aneurysm neck reendothelialization in rabbit saccular aneurysm after flow diverter treatment. Acta Biochim Biophys Sin (Shanghai) 2017;49:246-53 CrossRef Medline

9. Li Z, Zhao R, Fang X, et al. AMD3100 accelerates reendothelialization of neointima in rabbit saccular aneurysm after flow diverter treatment. World Neurosurg 2017;107:416-23 CrossRef Medline

10. Li ZF, Fang XG, Yang PF, et al. Endothelial progenitor cells contribute to neointima formation in rabbit elastase-induced aneurysm after flow diverter treatment. CNS Neurosci Ther 2013;19:352-57 CrossRef Medline

11. Marosfoi M, Langan ET, Strittmatter L, et al. In situ tissue engineering: endothelial growth patterns as a function of flow diverter design. J Neurointerv Surg 2017;9:994-98 CrossRef Medline

12. Matsuda Y, Chung J, Lopes DK. Analysis of neointima development in flow diverters using optical coherence tomography imaging. J Neurointerv Surg 2018;10:162-67 CrossRef Medline

13. Rouchaud A, Ramana C, Brinjikji W, et al. Wall apposition is a key factor for aneurysm occlusion after flow diversion: a histologic evaluation in 41 rabbits. AJNR Am J Neuroradiol 2016;37:2087-91 CrossRef Medline

14. Szikora I, Turányi E, Marosfoi M. Evolution of flow-diverter endothelialization and thrombus organization in giant fusiform aneurysms after flow diversion: a histopathologic study. AJNR Am J Neuroradiol 2015;36:1716-20 CrossRef Medline
15. Cebral JR, Mut F, Raschi M, et al. Analysis of hemodynamics and aneurysm occlusion after flow-diverting treatment in rabbit models. AJNR Am J Neuroradiol 2014;35:1567-73 CrossRef Medline

16. Chung B, Mut F, Kadirvel R, et al. Hemodynamic analysis of fast and slow aneurysm occlusions by flow diversion in rabbits. J Neurointerv Surg 2015;7:931-35 CrossRef Medline

17. Koh GY. Orchestral actions of angiopoietin-1 in vascular regeneration. Trends Mol Med 2013;19:31-39 CrossRef Medline

18. Brindle NP, Saharinen P, Alitalo K. Signaling and functions of angiopoietin-1 in vascular protection. Circ Res 2006;98:1014-23 CrossRef Medline

19. Pang $D$, Wang $L$, Dong J, et al. Integrin alpha5 $\beta 1$-Ang-1/Tie2 receptor cross-talk regulates brain endothelial cell responses following cerebral ischemia. Experimental \& Molecular Medicine 2018;50:117 CrossRef

20. Fukuhara S, Sako K, Minami T, et al. Differential function of Tie2 at cell-cell contacts and cell-substratum contacts regulated by angiopoietin-1. Nat Cell Biol 2008;10:513-26 CrossRef Medline

21. Hattori K, Dias S, Heissig B, et al. Vascular endothelial growth factor and angiopoietin-1 stimulate postnatal hematopoiesis by recruitment of vasculogenic and hematopoietic stem cells. J Exp Med 2001; 193:1005-14 CrossRef Medline

22. Benest AV, Salmon AH, Wang W, et al. VEGF and angiopoietin-1 stimulate different angiogenic phenotypes that combine to enhance functional neovascularization in adult tissue. Microcirculation 2006;13:423-37 CrossRef Medline

23. Chin-Quee SL, Hsu SH, Nguyen-Ehrenreich KL, et al. Endothelial cell recovery, acute thrombogenicity, and monocyte adhesion and activation on fluorinated copolymer and phosphorylcholine polymer stent coatings. Biomaterials 2010;31:648-57 CrossRef Medline

24. Cseh B, Fernandez-Sauze S, Grall D, et al. Autocrine fibronectin directs matrix assembly and crosstalk between cell-matrix and cellcell adhesion in vascular endothelial cells. J Cell Sci 2010;123(Pt 22): 3989-99 CrossRef Medline

25. Cebral JR, Mut F, Raschi M, et al. Aneurysm rupture following treatment with flow-diverting stents: computational hemodynamics analysis of treatment. AJNR Am J Neuroradiol 2011;32:27-33 CrossRef Medline

26. Parameswaran PK, Dai D, Ding YH, et al. Assessment of endothelialization of aneurysm wall over time in a rabbit model through CD31 scoring. JNIS 2018;10:888-91

27. Cook S, Wenaweser P, Togni M, et al. Incomplete stent apposition and very late stent thrombosis after drug-eluting stent implantation. Circulation 2007;115:2426-34 CrossRef Medline

28. Hodis S, Ding YH, Dai D, et al. Relationship between aneurysm occlusion and flow diverting device oversizing in a rabbit model. J Neurointerv Surg 2016;8:94-98 CrossRef Medline

29. Larrabide I, Aguilar ML, Morales HG, et al. Intra-aneurysmal pressure and flow changes induced by flow diverters: relation to aneurysm size and shape. AJNR Am J Neuroradiol 2013;34:816-22 CrossRef Medline

30. Dai D, Ding YH, Kelly M, et al. Histopathological findings following Pipeline embolization in a human cerebral aneurysm at the basilar tip. Interv Neuroradiol 2016;22:153-57 CrossRef Medline

31. Kulcsár Z, Houdart E, Bonafé A, et al. Intra-aneurysmal thrombosis as a possible cause of delayed aneurysm rupture after flow-diversion treatment. AJNR Am J Neuroradiol 2011;32:20-25 CrossRef Medline

32. Pandey AS, San Antonio JD, Addya S, et al. Mechanisms of endothelial cell attachment, proliferation, and differentiation on 4 types of platinum-based endovascular coils. World Neurosurg 2014;82:684-95 CrossRef Medline

33. Bavinzski G, Talazoglu V, Killer M, et al. Gross and microscopic histopathological findings in aneurysms of the human brain treated with Guglielmi detachable coils. J Neurosurg 1999;91:284-93 Medline

34. Szikora I, Seifert P, Hanzely Z, et al. Histopathologic evaluation of 
aneurysms treated with Guglielmi detachable coils or matrix detachable microcoils. AJNR Am J Neuroradiol 2006;27:283-88

35. Werner N, Kosiol S, Schiegl T, et al. Circulating endothelial progenitor cells and cardiovascular outcomes. N Engl J Med 2005;353:9991007 CrossRef Medline

36. den Dekker WK, Houtgraaf JH, Onuma Y, et al. Final results of the HEALING IIB trial to evaluate a bio-engineered CD34 antibody coated stent (GenousStent) designed to promote vascular healing by capture of circulating endothelial progenitor cells in CAD patients. Atherosclerosis 2011;219:245-52 CrossRef Medline

37. Niccoli G, Montone RA, Ferrante G, et al. The evolving role of inflammatory biomarkers in risk assessment after stent implantation. J Am Coll Cardiol 2010;23 56;1783-93 CrossRef Medline 